\title{
Análise do controle estrutural em microambientes a partir da relação topografia-pedologia na bacia do Rio Canhoto, Pernambuco, Brasil
}

The structural control analysis in the micro enviroments from the relationship between topography-pedology in the Canhoto's River Basin, Pernambuco, Brasil

\author{
Santos, L. D. J.; Lima, E. M. ${ }^{2}$; Cabral, C. J. ${ }^{3}$; Corrêa, A. C. B. ${ }^{4}$
}

leandrodiomerio@hotmail.com

\begin{abstract}
Resumo
O interesse deste trabalho foi estabelecer uma relação entre a constituição micro ambiental da bacia hidrográfica do Rio Canhoto pelo controle estrutural; ilustrados aqui pela relação topografia - pedologia. A bacia hidrográfica do Rio Canhoto, é uma micro bacia pertencente à Bacia Hidrográfica do Rio Mundaú, situada na região Agreste do Estado de Pernambuco. Os métodos utilizados foram baseados na geração de produtos gráficos expondo a configuração topográfica e a pedologia locais, em cruzamento com os dados climatológicos dos municípios partícipes da área de estudos. Os resultados fazem referência à participação das frentes de Leste no fomento à precipitação, diminuindo a medida que a topografia se torna mais elevada, repercutindo no balanço de calor, o que finda por contribuir à gênese de solos específicos, como reflexo do controle da estrutura à dinâmica ambiental local, alicerçando ainda a geração de microambientes.
\end{abstract}

Palavras-Chave: Controle Estrutural, Microambientes, Borborema

\begin{abstract}
Abstratc
The interest of this work was to establish a relationship between microenvironmental constitution of Canhoto's river basin by structural control; illustrated here by the ratio topography - pedology. The Canhoto's river basin, is a microbasin belonging to the Mundaú's River Basin, located in the Agreste region of Pernambuco. The methods used were based on the generation of graphics products exposing the topographic configuration and local soil conditions, in junction with the climatological data of the participants municipalities of the study area. The results refer to the participation of eastern fronts in promoting precipitation, decreasing as the topography becomes higher, reflecting the heat balance, which ended up contributing to the genesis of specific soil, reflecting the structure of control to local environmental dynamics, even basing the generation of microenvironments.
\end{abstract}

Keywords: Structural Control, microenvironments, Borborema

\section{INTRODUÇÃO}

Uma paisagem apresenta marcas que são o resultado dos processos que atuaram na sua construção, essas marcas contam a história de evolução desses ambientes (AB’SABER, 2003), que podem ser traduzidas pela tendência ao equilíbrio dos sistemas físicos e ambientais, ainda que em contínua dinâmica (HACK, 1960). O interesse deste

\footnotetext{
${ }^{1}$ Leandro Diomério João dos Santos, Grupo de Estudos do Quaternário do Nordeste do Brasil, UFPE, Recife-PE, Brasil.

${ }^{2}$ Évio Marcos de Lima, Grupo de Estudos do Quaternário do Nordeste do Brasil, UFPE, Recife-PE, Brasil. ${ }^{3}$ Cládio José Cabral,, Grupo de Estudos do Quaternário do Nordeste do Brasil, UFPE, Recife-PE, Brasil.

${ }^{4}$ Antonio Carlos de Barros Correa, Departamento de Ciências Geográficas / Grupo de Estudos do Quaternário do Nordeste do Brasil, UFPE, Recife-PE, Brasil.
} 
trabalho está em estabelecer uma relação entre a constituição micro ambiental da bacia hidrográfica do Rio Canhoto e o controle estrutural; ilustrados aqui pela relação topografia - pedologia.

A premissa exposta admite que a configuração topográfica local exerce controle na distribuição pluviométrica e na penetração de umidade dos sistemas sinóticos locais repercutindo nos balanços energético e químico dos sistemas físicos presentes, o que por fomentaria um desenvolvimento pedogenético da região. Os trabalhos de Ab'saber (1970) foram pioneiros neste tipo de investigação, estabelecendo relação entre topografia, clima, vegetação e pedologia na constituição de paisagens macroscópicas no país. A constituição morfológica de uma área pode influenciar no seu dinamismo climático, controlando os processos dentro de seus sistemas físicos (CHRISTOFOLETTI, 1999). Em Phillips (2002) tem-se que a relação entre a estrutura e o clima, se dá pela orientação processual da primeira sobre o segundo. Segundo esta perspectiva, a ativação climática dos processos erosivos repercute na distribuição do material em superfície como uma resposta isostática à condição do arranjo estrutural (PHILLIPS, 2002). Römer (2010) também acena para a afirmação de que os aplainamentos seguem mais bem conservados tanto mais evidente seja o controle estrutural; Teoria respaldada por Tavares (2015) em sua aplicação aos relevos elevados a Oeste da Borborema.

A bacia hidrográfica do Rio Canhoto (Figura 1), é uma micro bacia pertencente à Bacia Hidrográfica do Rio Mundaú, situada na região Agreste do Estado de Pernambuco. Esta região está inserida na porção meridional de um cinturão orogenético ativado ao final do Éon proterozóico, a Superfície Borborema (MABESOONE, 2002) possuindo uma característica morfológica específica, estando situada na vertente S/SE da superfície Borborema, com a nascente do canal principal na parte soerguida desse terreno, aproximadamente há $1000 \mathrm{~m}$ de altitude e tendo sua desembocadura a menos de $500 \mathrm{~m}$ de altitude, percorrendo trecho pouco maior que 60 kilômetros. A configuração estrutural, levou à construção de uma vertente escalonada na direção S-SE culminando em uma cimeira, caracterizada por uma superfície aplainada, com cicatrizes erosivas refletindo processos de retirada e distribuição do material (LIMA, 2014). 


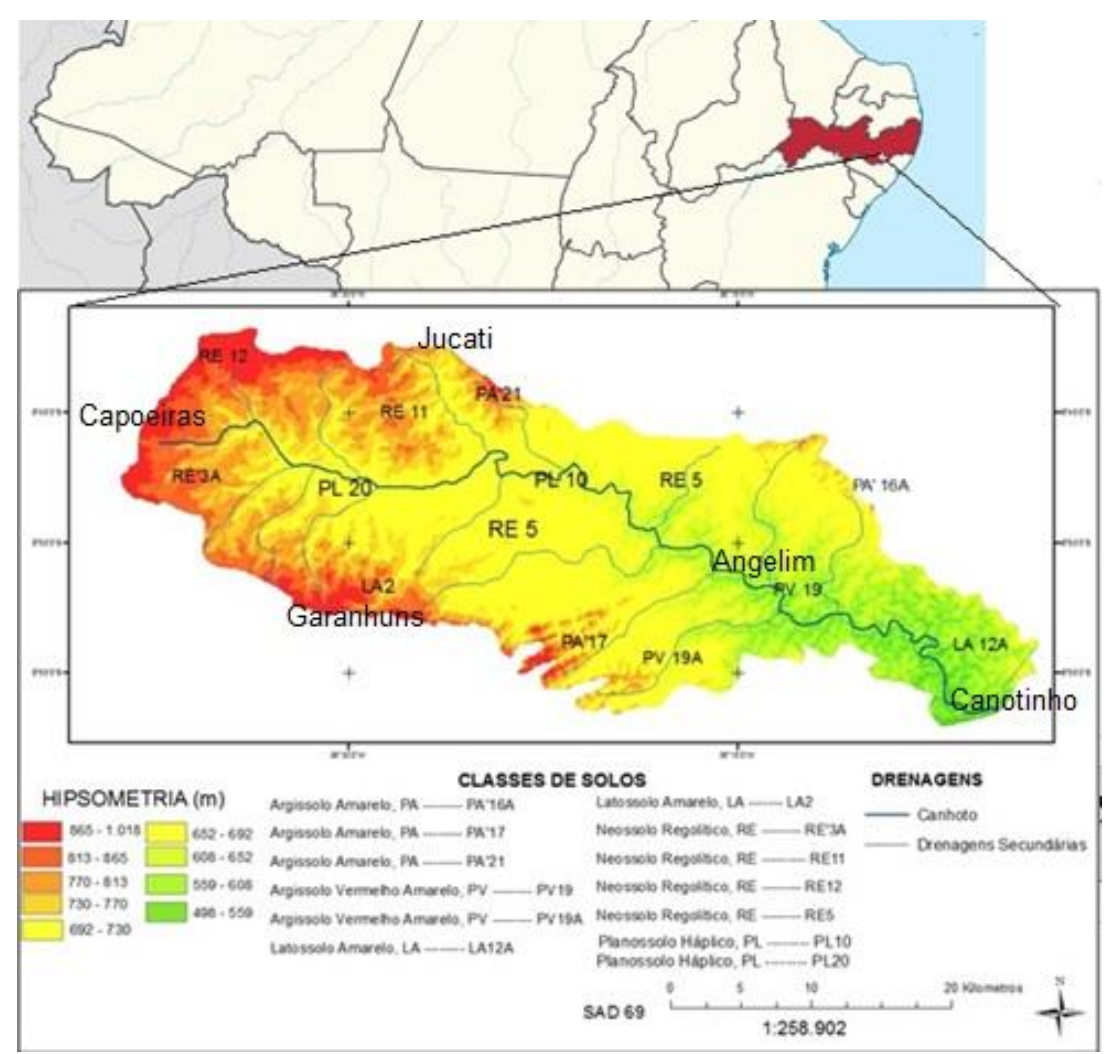

Figura 1: Localização da Bacia do Rio Canhoto, num contexto regional. Fonte: Autor.

A base analítica para a afirmação do controle estrutural de microambientes na área, foi feita a partir da distribuição pedológica alinhada a compartimentação topográfica local, onde, com o cruzamento de informações climáticas, Também sendo necessária uma investigação sobre a caracterização climática de alguns município partícipes da Bacia.

Toda análise teve o suporte de materiais gráficos, onde foram confeccionados mapas pedológicos e Modelos Digitais de Elevação - MDE's - que fomentaram as análises, servindo também de base para ilustração dos principais resultados obtidos.

\section{MATERIAIS E MÉTODOS}

Respeitando abordagens clássicas (AB'SABER, 1970; TRICART \& CAILLEUX, 1965; TRICART, 1977), os passos tomados neste trabalho, tiveram como ponto de partida a identificação dos tipos de solos presentes da área de estudos, através da construção de mapeamento pedológico com base nos dados do Zoneamento Agroecológico de Pernambuco - ZAPE - em cruzamento com o Modelo Digital de 
Elevação - MDE - construídos através de dados adquiridos, também, junto ao ZAPE. O mapa dos tipos de solo foi confeccionado seguindo o direcionamento do manual técnico de pedologia do Instituto Brasileiro de Geografia e Estatística - IBGE - (2007), para classificação, coloração e legenda do arcabouço gráfico. Para realização dos mapeamentos foi utilizado o software Arc Gis 10.1, em dependência das licenças disponibilizadas ao LabGEQUA. O MDE seguiu parâmetros já trabalhados por Gao (et. al. 2013) e Misatova (2012), onde é defendida a utilização desse material como alicerce de investigações ambientais, em justificativa à utilização da escala de 1:250.000 em mapeamentos, atribuída neste trabalho, em função do tamanho da bacia, bem como dos atributos que se buscou investigar, ou seja, as manchas de solo. Para o mapa de elevação foi utilizada uma base do tipo .TIFF, obtida junto à Missão Topográfica Radar Shuttle em inglês SRTM - através da sua página na web.

Ao final foram obtidas informações sobre ambientes genéticos para os tipos de solos e suas intersecções com compartimentos topográficos, a partir de leituras específicas (ARAÚJO FILHO, 2000; RUGGIERO, et. al. 2006; EMBRAPA, 2006; HAZELTON \& MURPHY, 2007; COGO, et. al. 2008; MEIRELES, et. al. 2012), gerando um baco de dados interligado a dados climáticos para localidades dentro da bacia, obtidos junto ao banco de dados "Climate-Data", através de seu sítio na internet. Foram ainda gerados perfis topográficos para facilitar a compreensão da relação que será estipulada entre o processo ambiental e a constituição pedogenética.

\section{RESULTADOS E DISCUSSÕES}

A discussão dos resultados segue os dados topográficos, climáticos, pedológicos, o cruzamento dessas informações e as conclusões obtidas.

\section{Dados topográficos}

O mapa topográfico (Figura 2) foi gerado já com as marcações dos solos identificados na área de estudos. Desta feita, é possível identificar uma variação dos tipos pedológicos, de certa forma, respeitando alguns padrões relacionados à topografia, sobretudo, no que tange à penetração da umidade.

$\mathrm{Na}$ imagem, se pode observar que a área alcança o cume no patamar acima dos $1000 \mathrm{~m}$ de altitude, enquanto que a bacia se projeta a elevações inferiores aos $500 \mathrm{~m}$, na desembocadura do Rio Canhoto. Em pouco mais de $60 \mathrm{~km}$ de extensão, a variação topográfica da bacia permite identificar uma vertente escalonada, distribuída em 3 setores: Elevado - entre 750 e 1018 m; Intermediário - entre 600 e 750 m; Inferior - 
abaixo dos $600 \mathrm{~m}$. Alinhado à uma verticalização cada vez menos abrupta, o leito do canal principal apresenta maior nível de meandros tanto menor for a altitude a qual estiver

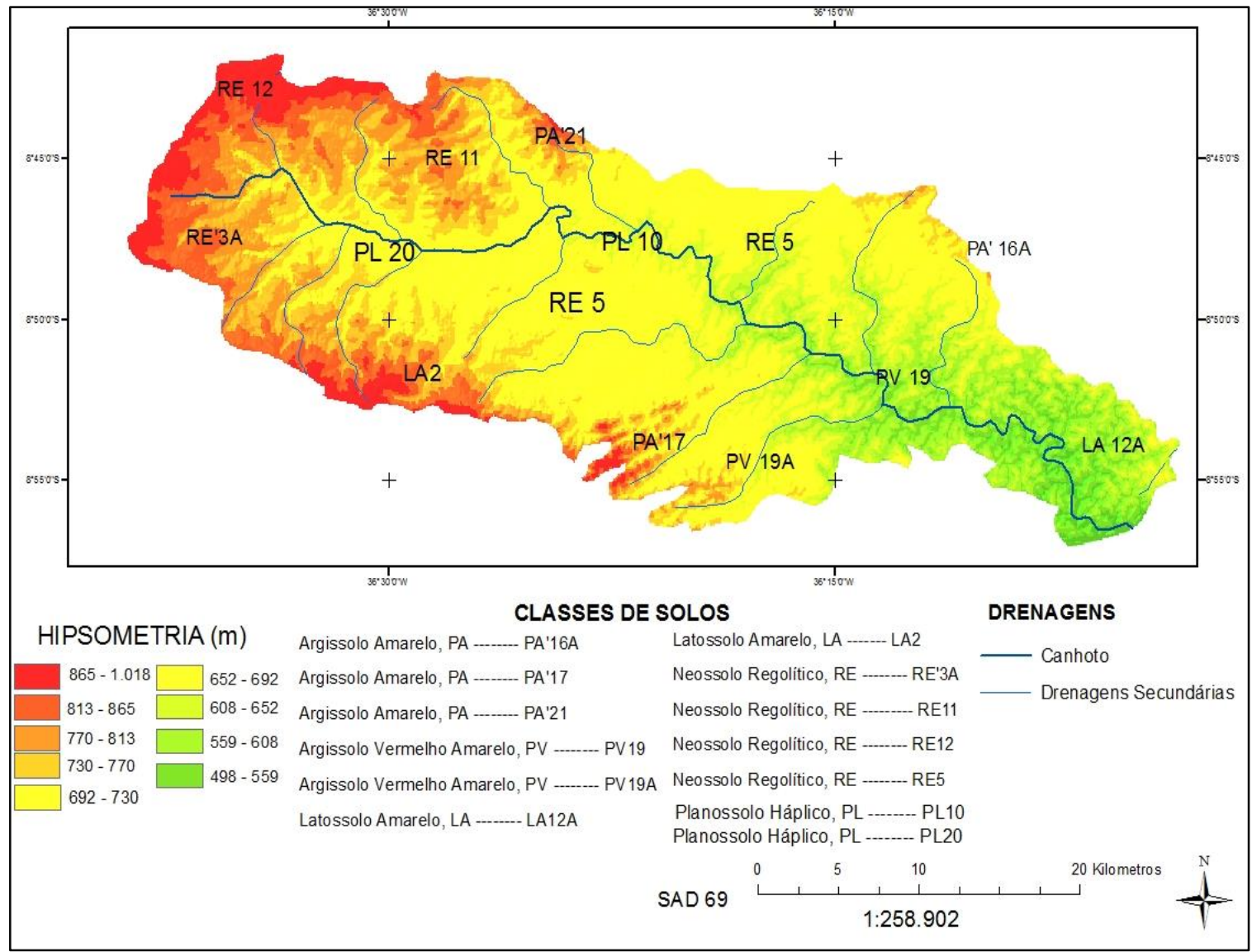

Inserido. Outra observação interessante faz referência a forte inclinação da vertente à N-

Figura 2: Modelo Digital de Elevação-MDE, retratando a relação entre a topografia e os tipos de solos recorrentes. Fonte: Autor.

NW, no transito entre os setores Intermediário e Elevado.

\section{Dados climáticos}

Os dados climáticos (Tabela 1) seguem alinhados às informações contidas em Lima (2014) e Molion \& Bernardo (2002) atestam a predominância dos eventos chuvosos relacionados à penetração da umidade relacionada ao bordo Leste do Vórtice Ciclônico de Altos Níveis (VCAN), enquanto migra, esta umidade precipita pela imposição da topografia, vertente acima, tendo seu transporte estagnado próximo à zona de cimeira.

Tabela 1: Soma média de precipitação - em mm - para o Município de Garanhuns, maior integrante da Bacia. Fonte: Lima, 2014.

\section{Tempera Média}




\begin{tabular}{lccc}
\hline Município & Max. Média & Min. Média & Precipitação mm/ ano \\
Capoeiras & 26,1 & 15,6 & 669 \\
Jucati & 26,5 & 15,5 & 711 \\
Garanhuns & 26,2 & 17,2 & 873 \\
Angelim & 28 & 18,1 & 903 \\
Canhotinho & 28,3 & 19,3 & 1034 \\
\hline
\end{tabular}

A temperatura média registrada na área também varia em função da topografia, sendo menor nas áreas próximas aos topos e maior próxima a desembocadura.

Os dados climáticos alinhados à topografia, sugerem a existência de topos ressequidos, pela dificuldade de precipitação oriunda do deslocamento deficitário das massas de lesta, ao passo que a temperatura nessas áreas é mais baixa, enquanto que as superfícies menos elevadas apresentam índices pluviométricos mais elevados, aliados às temperaturas também mais elevadas.

\section{Dados pedológicos}

Assumindo que o solo é produto das interações físico-químicas catalisadas pela água, o mapa de solos (Figura 3), deve ilustrar essa distribuição pela área de estudos.

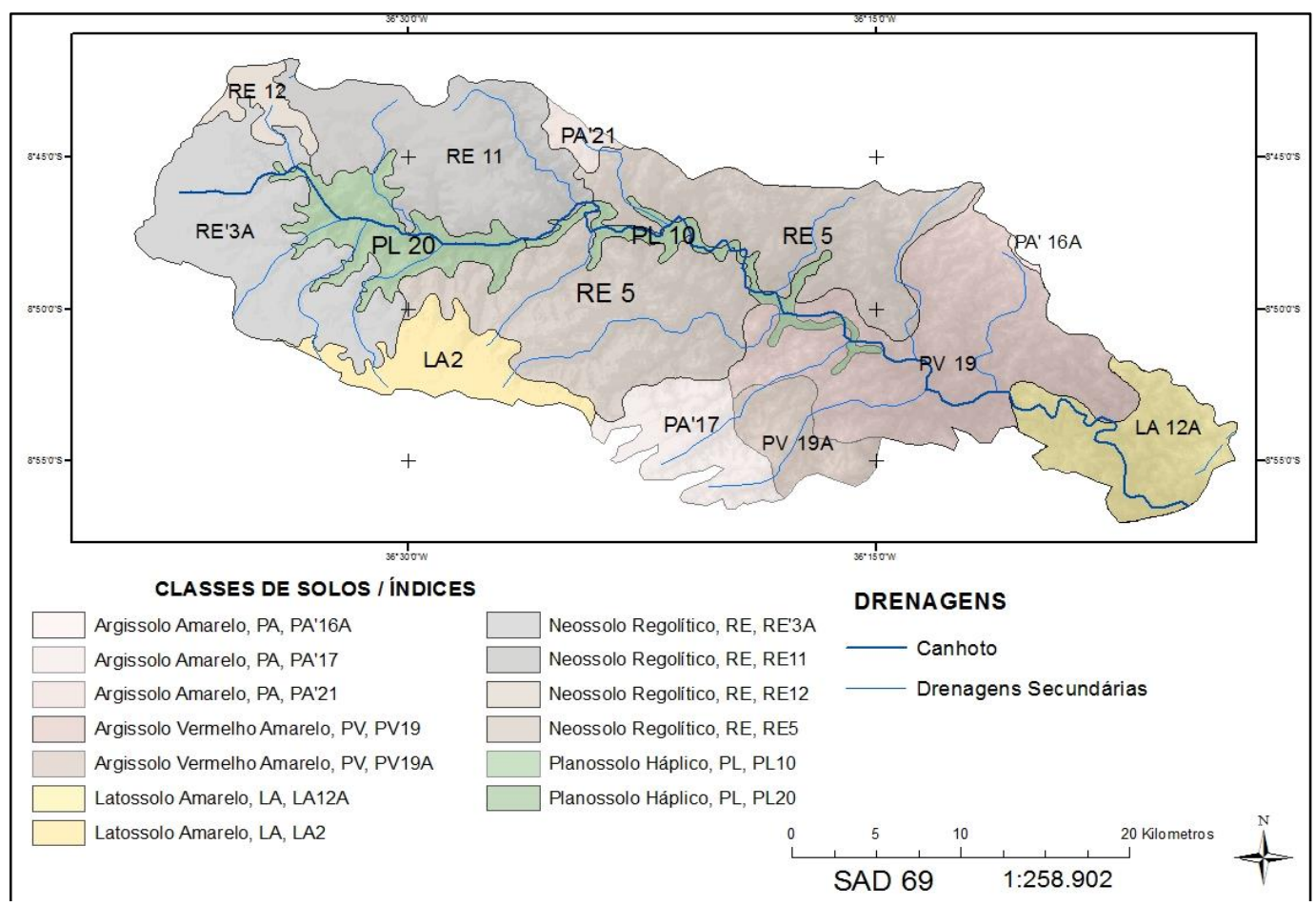

Figura 3: Mapa da distribuição pedológica na Bacia do Rio Canhoto. Fonte: Autor. 
$\mathrm{Na}$ análise por tipos de solos deve-se observar as características genéticas e o aspecto de cada tipo de solo, seguindo uma caracterização por tópicos, se observam:

Neossolos - Solos associados à climas secos (EMBRAPA, 2006). RE5 marca a zona de transição com o argissolo amarelo, apresentando maior profundidade e textura arenosa à média/argilosa. RE15, configura a zona de contato com planossolo. RE'3A, configura uma zona marcada por areias quartzosas, com e sem fragmentação e presença de gnaisses e granitos.

Argissolos amarelos - Distribuídos acompanhando as margens da bacia, com pouca ou quase nenhuma relação com o trabalho morfológico dos canais de primeira e segunda ordem, essas faixas recebem influência climática das frentes de E-SE em topos isolados - cristas e/ou inselbergs - percebendo um índice pluviométrico na ordem de $1.100 \mathrm{~mm} / \mathrm{ano}$, o que favorece os processos de pedogênese e a elaboração de solos úmidos.

Argissolos vermelho-amarelos - Distribuídos na faixa de transição para superfícies menos elevadas, a possível explicação desta distribuição se dá pela influência de processos hídricos no desenvolvimento de sua pedogênese, sobretudo à lavagem dos minerais mais finos, permitindo separação do Fe, bem como a constituição do horizonte Bt, maior que 1 m (EMBRAPA, 2006), estabelecendo uma relação direta com a altitude das superfícies, a distribuição de calor e umidade, favorecendo o trabalho pedológico.

Planossolos háplicos - São solos rasos cuja característica primordial é uma rápida mudança entre aspectos do horizonte $\mathrm{A}$ e o horizonte $\mathrm{B}$, de textura permeável para uma pouco permeável, de difícil aprofundamento. Segundo a EMBRAPA (2006), este tipo de solo pode ser associado à congruência entre os fatores climáticos, ambientados em pouca precipitação e temperaturas menores, variando em torno dos 20 ${ }^{\circ} \mathrm{C}$ de média, na presença de drenagem intermitente e vegetação de pequeno porte associada à caatinga. Estas características podem explicar seu maior desenvolvimento nas áreas próximas às cimeiras, nas faixas de alto curso do Rio Canhoto e a inexistência desta classe nas superfícies mais rebaixadas, com maior temperatura média.

Quando são elaborados os perfis topográficos (Figura 4), parece evidente a relação entre as áreas de topos, nesta região, com temperaturas mais baixas e menor volume pluviométrico, e a formação de solos pouco desenvolvidos como os Neossolos 
Regolíticos, enquanto que as superfícies menos elevadas, apresentando maior volume pluviométrico e maior temperatura, estão associadas ao desenvolvimento de solos mais bem desenvolvidos; em última instância, os cenários de exceção estão atribuídos topos isolados na forma de Cristas e Inselbergs, que parecem formar ilhas de umidade, favorecendo o desenvolvimento pedológico pontual.

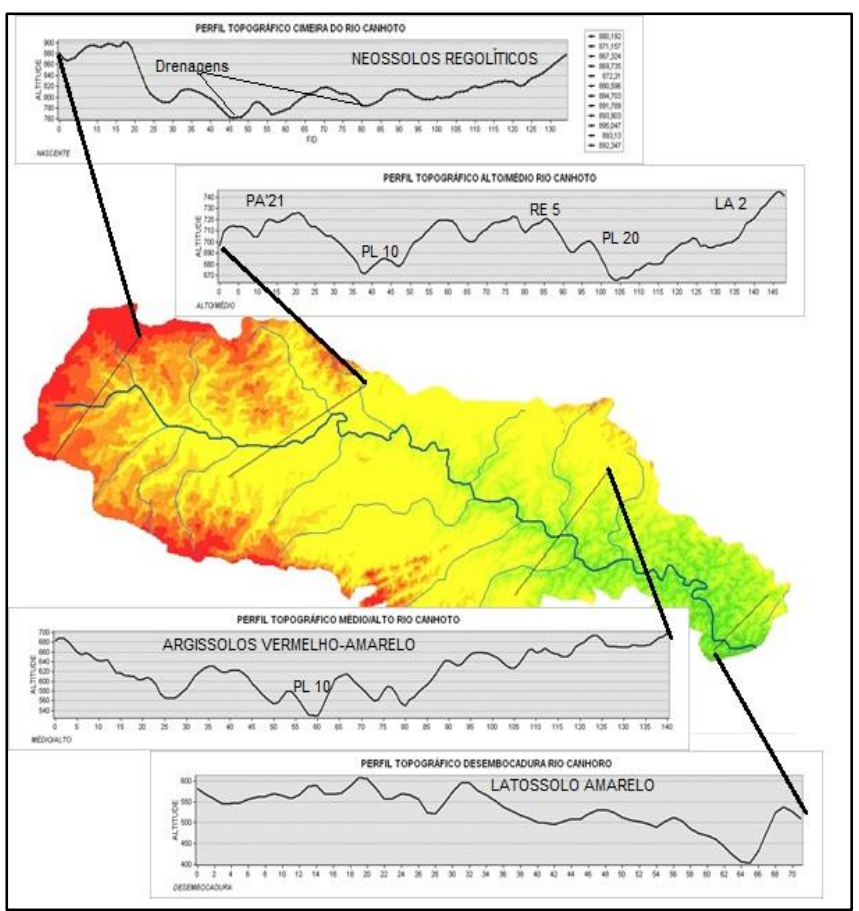

Figura 4: Perfis topográficos da Bacia do Rio Canhoto em 4 quadrantes, de cima pra baixo: Superfície mais elevada; Transição para alto/médio curso; Transição para médio/baixo curso; Superfície menos elevada. Fonte: Autor.

\section{CONSIDERAÇÕES FINAIS}

Os dados obtidos neste estudo, indicam que as características topográficas locais condicionam a distribuição pluviométrica e a variação termostática da área, influenciando diretamente no trabalho dos intemperismos e no desenvolvimento da pedogênese, acentuando a formação de microambientes difusos por toda extensão da bacia. A ascensão e basculamento do bloco oriental da Borborema favoreceram o desenvolvimento de uma topografia em degraus, no sentido reverso deste basculamento. A ação das condicionantes estruturais impondo a característica topográfica local pode também ter alicerçado uma transformação ambiental em microescala. O que se percebe com estas análises é a importância do arcabouço estrutural, regendo o dinamismo ambiental em superfície. Contrariamente ao esperado em um primeiro momento, as superfícies elevadas da Bacia do Rio Canhoto, associadas às zonas de planalto, não 
favorecem o desenvolvimento da pedogênese, uma vez que há déficit na disposição de água e suas temperaturas são significativamente menores às superfícies menos elevadas.

Como última apreensão deste trabalho, fica a evidência de sucesso do método proposto para este tipo de análise, enfatizando o papel do arcabouço gráfico, no labor da geografia, como ferramenta indispensável de análise e exposição dos resultados das pesquisas em todos os ramos desta ciência.

\section{REFERÊNCIAS}

AB'SÁBER, A. N. Os Domínios de Natureza no Brasil. Ed. Ateliê Editorial, São Paulo, SP. 2003.

AB'SÁBER, A. N. Províncias geológicas e domínios morfoclimáticos no Brasil. Geomorfologia, São Paulo, n. 20, p. 1-26, 1970.

ARAÚJO FILHO, J. C.; BURGOS, N.; LOPES, O. F.; SILVA, F. H. B. B.; MEDEIROS, L. A. R.; MÉlO FILHO, H. F. R.; PARAHYBA, R. B. V.; CAVAlCANTI, A. C.; OliveIRA NETO, M. B.; SILVA, F. B. R.; LEITE, A. P.; SANTOS, J. C. P.; SOUSA NETO, N. C.; SILVA, A. B.; LUZ, L. R. Q. P.; LIMA, P. C.; REIS, R. M. G.; BARROS, A. H. C. Levantamento de reconhecimento de baixa e média intensidade dos solos do estado de Pernambuco. Recife: Embrapa Solos UEP Recife; Rio de Janeiro: Embrapa Solos, 252 p. (Embrapa Solos. Boletim de Pesquisa, 11). 1 CD-ROM. 2000.

CHRISTOFOLETTI, A. Modelagem dos Sistemas Ambientais. São Paulo Ed. Edgard Blucher, 1999.

COGO, N.P.; VOLK, L.B.S. Inter-relação biomassa vegetal subterrâneaestabilidade de agregados-erosão hídrica em solo submetido a diferentes formas de manejo. R. Bras. Ci. Solo, 32:1713-1722, 2008.

Empresa Brasileira de Pesquisa Agropecuária - EMBRAPA. Sistema Brasileiro de Classificação de Solos. Ministério da Agricultura, Pecuária e Abastecimento. Governo Federal. $2^{\circ}$ Ed. Brasília, DF, 2006.

GAO, M.; ZEILINGER, G.; XU, X.; WANG, Q.; HAO, M. DEM and GIS analysis of geomorphic indices for evaluating recent uplift of the northeastern margin of the Tibetan Plateau, China. Geomorphology, nº 190, Pág. 61-72, 2013. 
HACK, J. T. Interpretation of erosion topography in humid temperated regions. Am. J. Sci., 258A:80-97. (Bradley volume), 1960.

HAZELTON, P. MURPHY, B. Interpreting Soil Test Results; What do all the numbers mean? CSIRO publish, Collingwood, Victoria, Australia, 2007.

INSTITUTO BRASILEIRO DE GEOGRAFIA E ESTATÍSTICA - IBGE. Manual Técnico de Pedologia. Ministério do Planejamento, Orçamento e Gestão. Governo Federal, Rio de Janeiro, RJ. $2^{\circ}$ Ed. 2007.

LIMA, E. M. Evolução Paleoambiental do Município de Garanhuns-PE, a partir de Análises Sedimentológicas: Aplicação do Método de Luminescência Opticamente Estimulada - LOE. Universidade Federal de Pernambuco - UFPE, Dissertação de Mestrado, 105f, 2014.

MABESOONE, J. N. História geológica da província borborema (ne brasil). Universidade Federal de Pernambuco. Revista de Geologia, Vol. 15: 119-129. Recife, 2002.

MEIRELES, H. T., MARQUES JÚNIOR, J., CAMPOS, M. C. C., PEREIRA, G. T. Relações Solo-Paisagem em Topossequência de Origem Basaltica. Pesquisa Agropecuária Tropical, Goiânia, n²,V.42, p. 129-136, 2012.

MITASOVA, H.; HARMON, R. S.; WEAVER, K. J.; LYONS, N. J.; OVERTON, M. F. Scientific Visualization of Landscapes and Landforms. Geomorphology, $\mathrm{n}^{\circ} \mathbf{1 3 7}$, pág. 122-137. 2012.

MOLION, L. C. B.; BERNARDO, S. O. Uma Revisão da Dinâmica das Chuvas no Nordeste Brasileiro. Revista Brasileira de Meteorologia, v. 17, n. 1, p 1-10, 2002 PHILlIPS, J. D. Erosion, Isostatic Response and the Missing Peneplans. Geomorphology, Ed. Elsevier, no 4, p. 225-241. 2002.

RÖMER, W. Multiple Planation Surfaces in Basemente Regions: Implications for the Reconstruction of Periods of Denudation and Uplift in Southern Zimbabwe. Geomorphology, ed. Elsevier, no 114, p. 199-212. 2010

RUGGIERO, P.G.C.; PIVELlO, V.R.; SPAVOREK, G.; TERAMOTO, E. \& PIRES NETO, A.G. Relação entre solo, vegetação e topografia em área de cerrado (Parque Estadual de Vassununga, SP): como se expressa em mapeamentos? Acta Botanica Brasilica 20: 383-394, 2006. 
TAVARES, B. A. C. Evolução Morfotectônica dos Pedimentos Embutidos no Planalto da Borborema. Tese de doutorado, Universidade Federal de PernambucoUFPE. Recife-PE, 251f, 2015.

TRICART, J. Ecodinâmica. Rio de Janeiro, IBGE/SUPREN. 1977.

TRICART, J. E CAILLEUX, A. Introduction a la géomorphologie climatique. Paris:SEDES, 1

Recebido em: 14/08/2016

Aceito para publicação em: 01/10/2016 